Check for updates

Cite this: RSC Adv., 2017, 7, 46629

Received 29th July 2017

Accepted 23rd September 2017

DOI: $10.1039 / c 7 r a 08374 b$

rsc.li/rsc-advances

\section{Biomass-derived nitrogen-doped hierarchically porous carbon networks as efficient absorbents for phenol removal from wastewater over a wide $\mathrm{pH}$ range}

\author{
Wenyi Du, ${ }^{a}$ Junting Sun, ${ }^{a}$ Yongxi Zan, ${ }^{a}$ Zhengping Zhang, ${ }^{\text {ab }}$ Jing Ji, ab Meiling Dou*ab \\ and Feng Wang (iD) *ab
}

Developing cost-effective porous carbon adsorbents with large adsorption capacity and superior recyclability over a wide $\mathrm{pH}$ range is critical for the efficient removal of toxic phenol from industrial wastewater. Herein, we demonstrate a facile and effective strategy for synthesis of a nitrogen-doped hierarchically porous carbon (NHPC) network derived from cattle bone as a highly efficient adsorbent for the removal of phenol from wastewater. The as-prepared NHPC possessed a high specific surface area $\left(2687 \mathrm{~m}^{2} \mathrm{~g}^{-1}\right)$, a unique three-dimensional (3D) hierarchical porous structure and high content of nitrogen doping (2.31 at\%). As a result, NHPC exhibited a remarkable adsorption performance towards phenol with a significantly large adsorption capacity of $431 \mathrm{mg} \mathrm{g}^{-1}$ (3.56-fold that of the commercial adsorbent (Norit CGP)), a high adsorption rate of $4.57 \mathrm{~g} \mathrm{mg}^{-1} \mathrm{~h}^{-1}$ (17-fold that of Norit CGP) and an outstanding recyclability with $98 \%$ of the initial adsorption capacity maintained after 5 cycles $(75 \%$ for Norit (GP). More importantly, the NHPC held almost the identical maximum adsorption capacity over a wide $\mathrm{pH}$ range of $2-9$, showing a good applicability in the removal of phenol from a variety of wastewaters. Thermodynamic and kinetics analyses indicated that the adsorption process was spontaneous and exothermic, which fitted well the Langmuir isotherm model and pseudo-second-order model. This biomass-based porous carbon with well-defined hierarchical porosity can be applied as a promising adsorbent for efficient removal of phenol from wastewater.

\section{Introduction}

Phenols that are commonly discharged from the wastewater of petroleum refineries and steel foundries, pose a great threat to the health and safety of both human beings and animals due to their high toxicity and carcinogenicity even at low concentrations. ${ }^{1}$ Many technologies including membrane separation, ${ }^{2}$ photocatalytic degradation, ${ }^{3}$ and adsorption ${ }^{4}$ have been developed for phenol removal from wastewater. Among them, the adsorption technique is regarded as a competitive and effective approach due to its simplicity and high efficiency. ${ }^{5,6}$ However, the poor recyclability of the adsorbents in the adsorption technique limits its performance, resulting in a high-cost and tedious procedure for the removal of phenols from wastewater. Consequently, great efforts have been devoted to the

\footnotetext{
${ }^{a}$ State Key Laboratory of Chemical Resource Engineering, Beijing Key Laboratory of Electrochemical Process and Technology for Materials, Beijing University of Chemical Technology, Beijing 100029, P. R. China. E-mail: wangf@mail.buct.edu. cn; douml@mail.buct.edu.cn; Fax: +86-10-64451996; Tel: +86-10-64451996

${ }^{b}$ Beijing Advanced Innovation Center for Soft Matter Science and Engineering, Beijing University of Chemical Technology, Beijing 100029, P. R. China
}

development of highly efficient, recyclable and low-cost adsorbents for the removal of phenols.

Over the past decades, porous carbon materials have been widely used as alternative adsorbents due to their relatively high adsorption performances originating from the large specific surface area, high porosity, and abundant surface functionalities. ${ }^{7-11}$ Unfortunately, the adsorption performance including adsorption capacity, adsorption rate and recyclability of most previously reported porous carbons are still far from satisfactory on the removal of phenol because of their torturous porous channels and numerous inaccessible micropores that limit the diffusion and adsorption of the phenol molecules in the pores. ${ }^{\mathbf{1 2 , 1 3}}$ In addition, their adsorption performances are also highly susceptible to the $\mathrm{pH}$ value of the target phenolcontaining wastewaters, ${ }^{\mathbf{1 4}, 15}$ which is hampering the largescale application of porous carbon adsorbents for industrial wastewaters with various $\mathrm{pH}$ values. To address these issues, it is essential for porous carbon absorbents to have a large specific surface area and an interconnected hierarchically micro-mesomacro-porous structure, in which the micropores can increase the amount of accessible adsorption sites, and the open meso/ macropores can promote the mass transport of phenols in 
wastewaters. Besides, the phenol absorption is determined not only by the " $\pi-\pi$ dispersion interaction" between the carbon basal plane and the phenol aromatic ring, but also by the "donor-acceptor effect" between the surface functional groups and the phenol molecules. ${ }^{\mathbf{1 6}, 17}$ In this regard, surface modification of porous carbon by nitrogen-containing functional groups (e.g., $-\mathrm{NH}_{2}$, pyrrolic $\mathrm{N}$, quaternary $\mathrm{N}$ ) plays an important role in the enhancement of adsorption performance of porous carbon absorbents due to the formation of donor-acceptor complex. ${ }^{18}$ Also, these nitrogen-containing functional groups on the porous carbon surfaces can be expected to alleviate the effect of solution $\mathrm{pH}$ on the phenol adsorption, ${ }^{\mathbf{1 6}}$ leading to an enhanced adsorption flexibility over a wide $\mathrm{pH}$ range. Based on these design principles, it is evident that the nitrogen-doped hierarchically porous carbons with large specific surface area are promising as efficient adsorbents for the removal of phenols from wastewaters.

Recently, biomass materials (e.g., cattle bone, ${ }^{19}$ chitosan $^{20}$ and silkworm cocoon $^{21}$ ) have emerged as a new platform for synthesizing the functional porous carbon materials due to their unique structural characteristics, abundant source and wide available features. As one kind of biomass wastes, animal bone consisting of organic collagens with ordered inorganic composites is an ideal precursor for synthesizing nitrogendoped porous carbon. ${ }^{22,23}$ The organic collagens can be converted to carbon with rich nitrogen doping, and the high porosity and three-dimensional (3D) ordered nano-architecture of animal bone can be partially preserved to afford large specific surface area of resultant porous carbon due to the template effect of ordered inorganic composites via a facile carbonization approach. In the present study, we developed a facile and effective strategy for synthesis of nitrogen-doped 3D hierarchical porous carbon (NHPC) networks as an efficient adsorbent for the removal of phenol from wastewater via the carbonization and $\mathrm{KOH}$ activation of cattle bone (Scheme 1). NHPC with nitrogen doping possessed a large specific surface area of $2687 \mathrm{~m}^{2} \mathrm{~g}^{-1}$ and a well-defined 3D hierarchically porous structure. As used as an adsorbent for phenol removal, the resultant NHPC exhibited a remarkable adsorption performance over a wide $\mathrm{pH}$ range with a large adsorption capacity, a high adsorption rate and an outstanding recyclability, far superior to that of the commercial porous carbon adsorbent NORIT CGP SUPER (Norit CGP, activated carbon).

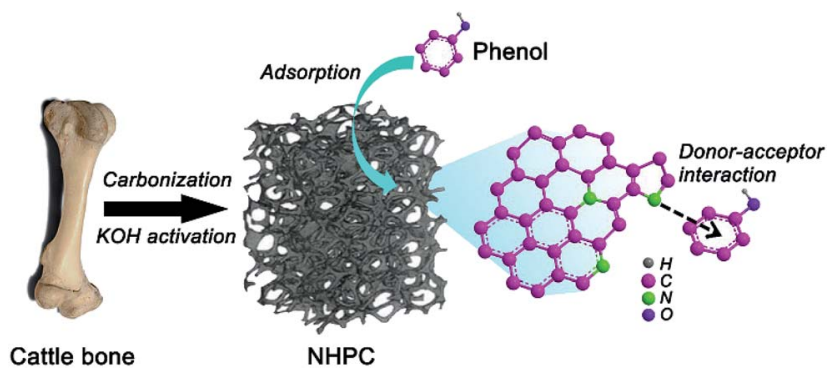

Scheme 1 Schematic illustration of synthetic process of NHPC for efficient removal of phenol.

\section{Materials and methods}

\subsection{Adsorbents and reagents}

The dried cattle bone powder was purchased from market in Beijing. High-purity Ar gas (99.99\%) was bought from Beijing AP BAIF Gases Industry Co., Ltd. Potassium hydroxide $(\mathrm{KOH})$ and hydrogen nitrate $\left(\mathrm{HNO}_{3}\right)$ were analytical grade produced by Sinopharm. The Norit CGP was purchased from Norit company (Beijing). Ultrapure water (Millipore, $18.2 \mathrm{M} \Omega \mathrm{cm}$ ) was used throughout the preparation. All the materials were used as received without further purification.

\subsection{Synthesis of NHPC}

The NHPC was synthesized by pyrolyzing the dried cattle bone powder based on the previous work. ${ }^{19}$ Briefly, the dried cattle bone powder was firstly pre-carbonized at $400{ }^{\circ} \mathrm{C}$ for $3 \mathrm{~h}$ in an $\mathrm{Ar}$ atmosphere and then mixed with $\mathrm{KOH}$ at an optimized mass ratio of 1.67. Subsequently, the mixture was transferred into the tubular furnace and carbonized at $800{ }^{\circ} \mathrm{C}$ for $1 \mathrm{~h}$ in an $\mathrm{Ar}$ atmosphere. After carbonization with $\mathrm{KOH}$-activation, the product was washed with $2 \mathrm{~mol} \mathrm{~L}{ }^{-1} \mathrm{HNO}_{3}$ followed by rinsing with ultrapure water until the filtrate was neutral, and then dried at $120{ }^{\circ} \mathrm{C}$ for $24 \mathrm{~h}$ under vacuum to obtain NHPC.

\subsection{Characterizations}

Scanning electron microscopy (SEM) was performed with a field emission scanning electron analyzer (FE-JSM-6701F, JEOL, Japan) operating at an accelerating voltage of $10 \mathrm{kV}$. Transmission electron microscope (TEM) was carried out on a (JSM-2100 instrument (JOEL, Japan)) operating at $300 \mathrm{kV} . \mathrm{N}_{2}$ adsorption-desorption measurements were performed with an automatic Quantachrome II analyzer to evaluate the total specific surface area (based on the Brunauer-Emmett-Teller (BET) model) and pore-size distribution (based on the density functional theory (DFT) model) of the absorbents. Fourier transform infrared spectroscopy (FT-IR) (Nicolet 6700, USA) and X-ray photoelectron spectroscopy (XPS) (ESCALAB-250, Thermo Fisher Scientific, USA) analyses were used to determine the element composition and surface chemical state of the absorbents. The concentration of phenol in aqueous solution was determined using ultraviolet spectrophotometer (UV-2450, Japan) at a wavelength of $269.5 \mathrm{~nm}$.

\subsection{Adsorption of phenol}

Batch adsorption of phenol experiments were conducted with a reciprocal shaker bath (Chunlan Co., Ltd.). Prior to adsorption, $1000 \mathrm{mg} \mathrm{L^{-1 }}$ phenol solution was firstly prepared by diluting the stock solution using deionized water. The $\mathrm{pH}$ value of phenol solution was adjusted by $0.01 \mathrm{~mol} \mathrm{~L}^{-1} \mathrm{HCl}$ or $0.01 \mathrm{~mol} \mathrm{~L}^{-1} \mathrm{NaOH}$. Afterwards, $0.01 \mathrm{~g}$ of as-prepared NHPC was added in a vial with $10 \mathrm{~mL}$ of phenol solution (the phenol concentration of $125 \mathrm{ppm}$ ) and rotated at $130 \mathrm{rpm}$ for $4 \mathrm{~h}$ at $303 \mathrm{~K}$. After adsorption equilibrium, the solution was filtered, and the filtrate was collected to analyze the phenol concentration. For comparison, the adsorption of phenol with Norit CGP 
was also conducted under the identical conditions. The equilibrium adsorption capacity of phenol $\left(q_{\mathrm{e}}, \mathrm{mg}^{-1}\right)$ was calculated according to the following equation: ${ }^{8}$

$$
q_{\mathrm{e}}=\left(C_{0}-C_{\mathrm{e}}\right) / m \times V
$$

where, $V(\mathrm{~L})$ is the volume of the phenol solution, $C_{0}\left(\mathrm{mg} \mathrm{L}^{-1}\right)$ and $C_{\mathrm{e}}\left(\mathrm{mg} \mathrm{L}^{-1}\right)$ are the initial and equilibrium concentration of phenol, respectively, and $m(\mathrm{~g})$ is the mass of NHPC used.

Langmuir (eqn (2)) and Freundlich models (eqn (3)) were applied to fit the adsorption data to describe the adsorption equilibrium of NHPC and Norit CGP. ${ }^{23}$

$$
\begin{gathered}
q_{\mathrm{e}}=q_{\mathrm{m}} \times b \times C_{\mathrm{e}} /\left(1+b \times C_{\mathrm{e}}\right) \\
q_{\mathrm{e}}=K_{\mathrm{F}} \times C_{\mathrm{e}}^{1 / n}
\end{gathered}
$$

where, $C_{\mathrm{e}}\left(\mathrm{mg} \mathrm{L}^{-1}\right)$ is the equilibrium concentration of phenol, $q_{\mathrm{e}}\left(\mathrm{mg} \mathrm{g}^{-1}\right)$ is the amount of phenol adsorbed, $q_{\mathrm{m}}\left(\mathrm{mg} \mathrm{g}^{-1}\right)$ is the saturate adsorption capacity of phenol, $b\left(\mathrm{~L} \mathrm{mg}^{-1}\right)$ is the Langmuir isotherm coefficient, $K_{\mathrm{F}}\left(\mathrm{mg} \mathrm{g}^{-1}\right)$ and $n$ are the Freundlich constants.

\subsection{Adsorption kinetics and thermodynamic}

Pseudo-first-order (eqn (4)) and pseudo-second-order (eqn (5)) models were used to investigate the adsorption kinetics of phenol removal. ${ }^{23}$

$$
\begin{gathered}
\log \left(q_{\mathrm{e}}-q_{t}\right)=\log q_{\mathrm{e}}-k t / 2.303 \\
t / q_{t}=1 /\left(k q_{\mathrm{e}}^{2}\right)+t / q_{\mathrm{e}}
\end{gathered}
$$

where, $q_{\mathrm{e}}\left(\mathrm{mg} \mathrm{g}^{-1}\right)$ is the adsorption capacity, $q_{t}\left(\mathrm{mg} \mathrm{g}^{-1}\right)$ is the adsorption capacity at time $(\mathrm{h})$, and $k\left(\mathrm{~g} \mathrm{mg}^{-1} \mathrm{~h}^{-1}\right)$ is the rate constant of the adsorption process.

Thermodynamic analysis of phenol adsorption was also investigated according to eqn (6) and (7) to calculate the thermodynamic parameters including Gibbs free energy change $\left(\Delta G, \mathrm{~kJ} \mathrm{~mol}^{-1}\right)$, enthalpy change $\left(\Delta H, \mathrm{~kJ} \mathrm{~mol}^{-1}\right)$ and entropy change $\left(\Delta S, \mathrm{~J} \mathrm{~mol}^{-1} \mathrm{~K}^{-1}\right){ }^{24}$

$$
\Delta G=-R T \ln b
$$

$$
\ln \mathrm{b}=\Delta S / R-\Delta H /(R T)
$$

where, $R\left(8.314 \mathrm{~kJ} \mathrm{~mol}^{-1} \mathrm{~K}^{-1}\right)$ is the ideal gas constant, $T(\mathrm{~K})$ is the adsorption temperature, and $b\left(\mathrm{~L} \mathrm{~mol}^{-1}\right)$ is the Langmuir constant.

\subsection{Regeneration experiment}

After the equilibrium adsorption in phenol solution, the adsorbents were washed with ethanol in the reciprocal shaker bath for several times to remove the adsorbed phenol and then dried under vacuum at $303 \mathrm{~K}$ for $24 \mathrm{~h}$ for regeneration. Afterwards, the regenerated adsorbents were reused for the adsorption of phenol in the consecutive adsorption-desorption cycles.

\section{Results and discussion}

\subsection{Physicochemical characterization}

The as-prepared NHPC was first characterized by SEM, TEM, and $\mathrm{N}_{2}$ adsorption-desorption measurements to investigate the microstructure and porosity properties. The representative SEM and TEM images (Fig. 1) combined with $\mathrm{N}_{2}$ adsorptiondesorption analysis (Fig. 2a) shows that the NHPC exhibits a 3D hierarchically porous structure with abundant micropores (1$2 \mathrm{~nm}$, micropore surface area of $1072 \mathrm{~m}^{2} \mathrm{~g}^{-1}$ ) along with interconnected open mesopores (2-6 nm) and macropores (50-200 nm). The total specific surface area and pore volume of NHPC are determined as $2687 \mathrm{~m}^{2} \mathrm{~g}^{-1}$ and $2.1 \mathrm{~cm}^{3} \mathrm{~g}^{-1}$, respectively, significantly higher than those of Norit CGP $\left(1929 \mathrm{~m}^{2} \mathrm{~g}^{-1}\right.$ and $1.37 \mathrm{~cm}^{3} \mathrm{~g}^{-1}$ ) and most reported biomassbased porous carbon phenol adsorbents (Table 1). The larger specific surface area along with the abundant micropores are favorable for the enhancement of adsorption capacity by providing sufficient adsorption sites, while the interconnected open meso/macropores are believed to promote the mass transfer of phenol, leading to an improved adsorption rate of NHPC.

Besides the porosity properties, the configuration of surface functional groups is considered another important factor that determines the adsorption behavior of the porous carbon adsorbents for phenol removal. The FT-IR spectrum of NHPC in Fig. $2 \mathrm{~b}$ exhibits the stretching vibrations of $\mathrm{O}-\mathrm{H} \& \mathrm{~N}-\mathrm{H}$ (3439 $\left.\mathrm{cm}^{-1}\right), \mathrm{C}-\mathrm{H}\left(2921 \mathrm{~cm}^{-1}\right.$ and $\left.2852 \mathrm{~cm}^{-1}\right), \mathrm{C}=\mathrm{O} \& \mathrm{C}=\mathrm{N}$ $\left(1618 \mathrm{~cm}^{-1}\right)$, and $\mathrm{C}-\mathrm{O}\left(1222 \mathrm{~cm}^{-1}\right)$. The $\mathrm{O}-\mathrm{H}, \mathrm{C}=\mathrm{O}$ and $\mathrm{C}-\mathrm{O}$ groups are probably contributed from the etching effect of $\mathrm{KOH}$ on the porous carbon networks during activation process. The existence of nitrogen-containing functional groups (i.e., $\mathrm{N}-\mathrm{H}$ and $\mathrm{C}=\mathrm{N}$ ) are derived from the carbonization of the organic collagens in cattle bone. The surface contents of $\mathrm{O}$ and $\mathrm{N}$ elements are determined as 12.37 at $\%$ and 2.31 at\% by XPS measurement, respectively. The high-resolution $\mathrm{N} 1 \mathrm{~s}$ spectra of NHPC before and after the adsorption of phenols (Fig. 2c and d) can be deconvoluted into four peaks located at approximately $399.5 \mathrm{eV}, 400.5 \mathrm{eV}, 401.2 \mathrm{eV}$, and $402.2 \mathrm{eV}$, showing the presence of pyridinic $\mathrm{N}$, pyrrolic $\mathrm{N}$, graphitic $\mathrm{N}$ and oxidized $\mathrm{N}$, respectively.

To explore the effect of these surface functional groups on the adsorption of phenol, the surface physicochemical
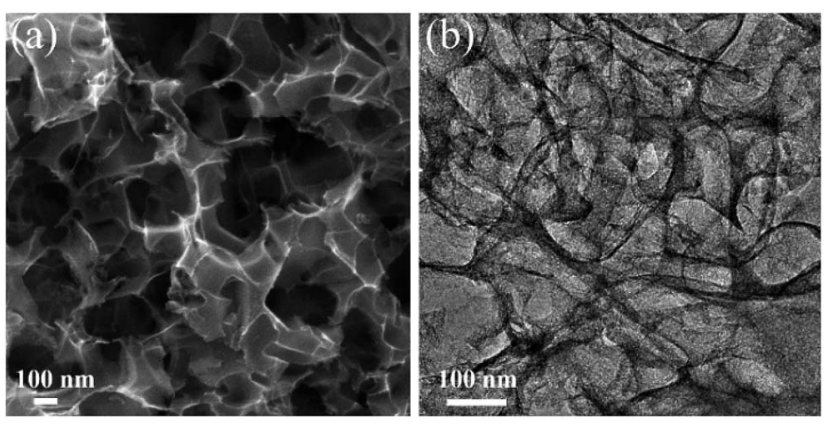

Fig. 1 Representative (a) SEM and (b) TEM images of NHPC. 

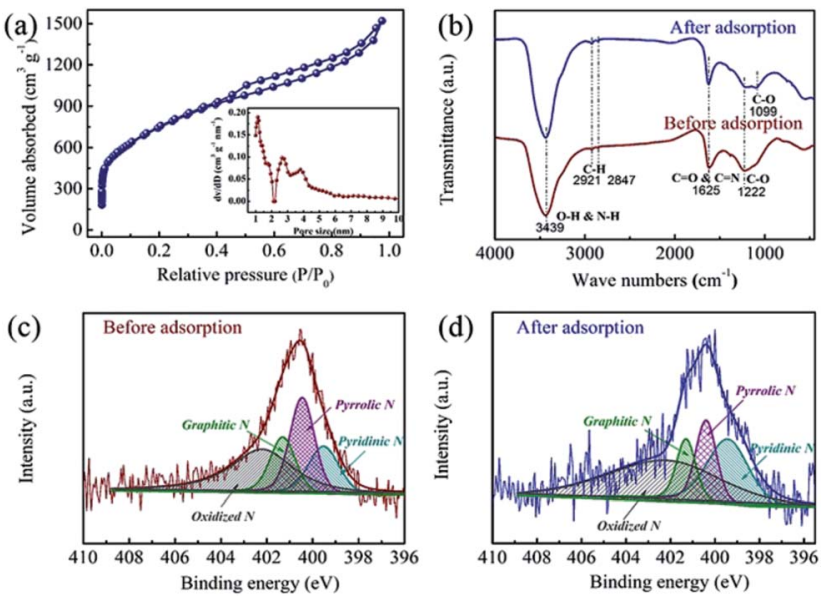

Fig. 2 (a) $\mathrm{N}_{2}$ adsorption-desorption isotherm (inset: pore size distribution) of NHPC, (b) FT-IR spectra of NHPC before and after phenol adsorption, and high-resolution XPS N 1s spectra of NHPC (c) before and (d) after phenol adsorption.

properties of NHPC after adsorption were also characterized. FT-IR spectrum (Fig. 2b) of NHPC presents a distinct peak located at approximately $1098.6 \mathrm{~cm}^{-1}$ after the adsorption of phenol, which is associated with the vibration of phenolic type $\mathrm{C}-\mathrm{O}$ bond ${ }^{25}$ indicating the adsorption of phenol on NHPC. The XPS analysis of the N 1s spectrum of NHPC after adsorption in Fig. 2d shows an obvious decrease of pyrrolic $\mathrm{N}$ (from 27.5 to 17.1 at\%) accompanied with an increase of pyridinic $\mathrm{N}$ (from 17.1 to 26.9 at\%) and a slight changes of graphitic N and oxidized $\mathrm{N}$ in comparison with those of NHPC before adsorption (Fig. 2c). The variation of $\mathrm{N}$ configuration before and after the phenol adsorption implies that the surface nitrogen groups are interacted with phenol molecule, and the pyrrolic $\mathrm{N}$ may contribute to the formation of donor-acceptor complex with phenol molecule by donating the lone pair electrons, ${ }^{17}$ promoting the adsorption of phenol on NHPC.

\subsection{Adsorption performance}

3.2.1. Effect of the solution $\mathbf{p H}$. To evaluate the adsorption performance of NHPC for the removal of phenol from wastewater, effects of the solution $\mathrm{pH}$, initial phenol concentration and contact time on the adsorption capacity were investigated and compared with Norit CGP. The effect of the solution $\mathrm{pH}$ on the adsorption capacity of NHPC (Fig. 3a) shows that its maximum adsorption capacity is approximately $110 \mathrm{mg} \mathrm{g}^{-1}$ as the $\mathrm{pH}$ ranging from 2 to 9 , significantly higher than that of Norit CGP $\left(60 \mathrm{mg} \mathrm{g}^{-1}\right)$. This feature can be attributed to the fact that the NHPC possesses a large specific surface area and welldefined 3D hierarchical porous structure to host the adsorbed phenol molecule, and the existence of surface carbonyl and pyrrolic $\mathrm{N}$ groups may attract the phenol molecule onto the surface through the " $\pi-\pi$ dispersion interaction" and "donoracceptor effect". ${ }^{17}$ It is worth noting that the adsorption capacity of NHPC remains almost the same over the $\mathrm{pH}$ range of $2-9$,
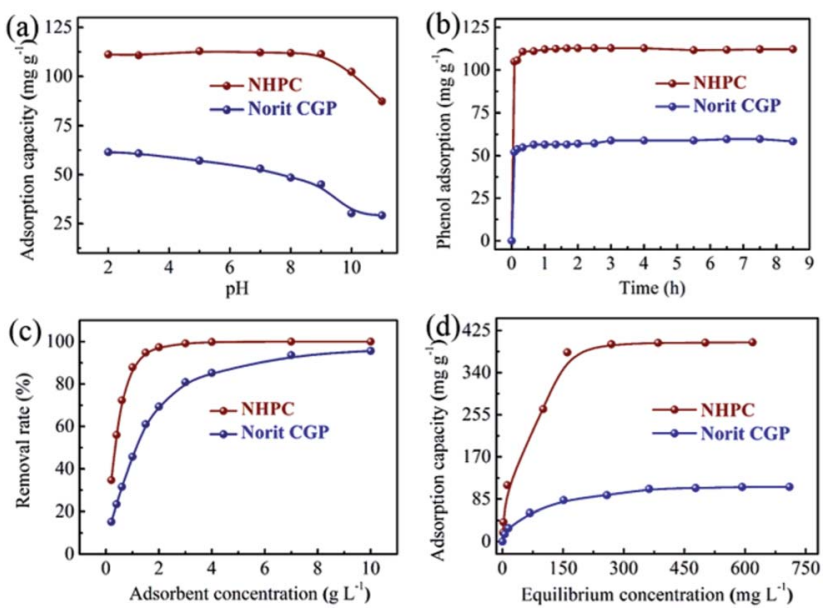

Fig. 3 Effect of (a) the solution $\mathrm{pH}$, (b) initial phenol concentrations, and (c) contact time on the adsorption capacities of NHPC and Norit CGP. (d) Adsorption isotherms of NHPC and Norit CGP at $303 \mathrm{~K}$.

Table 1 Summary of the phenol adsorption performance of absorbents reported in the literature

\begin{tabular}{|c|c|c|c|c|c|c|}
\hline Adsorbents & $\operatorname{BET}\left(\mathrm{m}^{2} \mathrm{~g}^{-1}\right)$ & $Q\left(\mathrm{mg} \mathrm{g}^{-1}\right)$ & $\mathrm{pH}$ & $K\left(\mathrm{~g} \mathrm{mg}^{-1} \mathrm{~h}^{-1}\right)$ & Recyclability & Ref. \\
\hline Coffee residue derived carbon & 520 & 88.31 & 3 & - & - & 12 \\
\hline Seeds derived carbon & 206 & 90 & $4-8.5$ & 13.56 & - & 13 \\
\hline Eggshells derived carbon & 113 & 192 & 5.2 & - & - & 26 \\
\hline Soybean straw derived carbon & 2271 & 208 & - & - & - & 27 \\
\hline Corn grain derived carbon & 2135 & 256 & $3-6$ & 0.96 & - & 28 \\
\hline Au NPs & - & 6.54 & 4 & 0.62 & $90 \%$ & 31 \\
\hline Rattan sawdust derived activated carbon & - & 149.25 & - & - & - & 32 \\
\hline Granular activated carbon & - & 165.80 & - & - & - & 33 \\
\hline Commercial activated carbon & - & 49.72 & - & - & - & 34 \\
\hline Sugarcane bagasse fly ash & - & 23.832 & - & - & - & 35 \\
\hline Activated carbon-commercial grade & - & 30.2187 & - & - & - & 35 \\
\hline
\end{tabular}


much different from Norit CGP with obviously decreased adsorption capacity as the $\mathrm{pH}$ value increased, indicating that the NHPC is more robust against the $\mathrm{pH}$ value and favorable for phenol removal from wastewaters with various $\mathrm{pH}$ values. The stable adsorption capacity over the $\mathrm{pH}$ range of 2-9 for NHPC may be attributed to the abundant surface oxygenated and nitrided groups which are capable of alleviating the effect of solution $\mathrm{pH}$ on phenol adsorption. ${ }^{\mathbf{1 6}}$ However, it should be mentioned that the adsorption capacities of both NHPC and Norit CGP suddenly decrease as the solution $\mathrm{pH}$ exceeds 9. At such $\mathrm{pH}$ value, the dissociation of phenol occurrs since the $\mathrm{p} K_{\mathrm{a}}$ of phenol is 9.98. ${ }^{17}$ The resultant phenolate anions (negative charge) repels the negative charged surface of NHPC $(\mathrm{pH}>$ $\left.\mathrm{pH}_{\mathrm{pzc}}=3.4\right)$ due to the electrostatic interaction between the phenolate anions and NHPC, leading to a decrease of adsorption capacity. In addition, the decreased adsorption capacity is also attributed to the stronger interaction between water and phenolate anions that is more soluble in aqueous solution. ${ }^{\mathbf{1 6}}$

3.2.2. Effect of contact time and initial phenol concentration. Apart from the flexibility of solution $\mathrm{pH}$, rapid adsorption with a short time is also extremely important for the efficient removal of phenol for industrial applications. Fig. 3b shows the variations of the adsorption capacities of both NHPC and Norit CGP in the function of contact time at the initial phenol concentration of $125 \mathrm{ppm}$. It is apparent that the adsorption of phenol on NHPC can quickly reach the adsorption equilibrium with a shorter contact time $(1 \mathrm{~h})$ than that of Norit CGP $(4 \mathrm{~h})$. Also, approximately $83.9 \%$ and $41.5 \%$ of phenol can be removed by NHPC and Norit CGP within only 5 minutes, respectively, suggesting a faster adsorption rate of phenol on NHPC than Norit CGP. The relatively high adsorption rate of NHPC is mainly attributed to the high-flow mass transport of phenol from solution to the adsorption sites on NHPC due to its welldefined interconnected open meso/macropores. Additionally, the effect of initial phenol concentrations on the adsorption capacities of NHPC and Norit CGP was also investigated (Fig. 3c). The adsorption capacities of NHPC and Norit CGP increase as increasing the adsorbent concentration (from 0.2 to $10 \mathrm{~g} \mathrm{~L}^{-1}$ ), and keep constant as the initial phenol concentration exceeds $3 \mathrm{~g} \mathrm{~L}^{-1}$ and $10 \mathrm{~g} \mathrm{~L}^{-1}$ for NHPC and Norit CGP, respectively. The maximum phenol removal rate is determined as almost $98 \%$ for NHPC, rather higher than that of Norit CGP (75\%), further confirming the superior adsorption performance of NHPC.

\subsection{Adsorption isotherms}

Fig. 3d shows the adsorption isotherm of NHPC recorded at $303 \mathrm{~K}$ at various initial phenol concentrations $\left(20-819 \mathrm{mg} \mathrm{L}^{-1}\right)$. The NHPC exhibits a significantly larger adsorption capacity (18-401 $\left.\mathrm{mg} \mathrm{g}^{-1}\right)$ than that of Norit CGP (15-109 $\left.\mathrm{mg} \mathrm{g}^{-1}\right)$ even at low initial phenol concentrations, which is attributed to its hierarchically porous structure with large specific surface area that provides sufficient accessible adsorption sites. The Langmuir isotherm model (eqn (2)) and Freundlich isotherm model (eqn (3)) have been applied to describe the adsorption behavior of phenol on NHPC (Table 2). The adsorption isotherm data can be better defined by the Langmuir model with a high correlation coefficient value $\left(R^{2}>0.99\right)$, indicating a monolayer adsorption behavior. The maximum adsorption capacity of NHPC is calculated as high as $431 \mathrm{mg} \mathrm{g}^{-1}$, which is 3.56 -fold the corresponding value of Norit CGP $\left(121 \mathrm{mg} \mathrm{g}^{-1}\right)$ and much higher than those of most reported porous carbon adsorbents (Table 1). The significantly higher adsorption capacity of NHPC compared with Norit CGP is attributed to the larger specific surface area and pore volume of NHPC (1.4 and 1.7-fold that of Norit CGP, respectively), which can increase absorption sites and facilitate mass transfer for phenol. In addition, the surface $\mathrm{N}$-containing groups of NHPC also contribute to the enhancement of adsorption performance due to the formation of donoracceptor complex.

\subsection{Adsorption kinetics and thermodynamics}

The adsorption kinetics of NHPC were investigated based on the pseudo-first-order (eqn (4)) and pseudo-second-order models (eqn (5)). The calculated correlation coefficient values $\left(R^{2}\right)$ in Table 3 indicates that the adsorption process is well described by the pseudo-second-order model with a much larger $R^{2}(1.00)$ than that of pseudo-first-order model (0.82), which is similar as that of the biosorption of $\mathrm{Cd}(\mathrm{II})^{36}$ and $\mathrm{Pb}(\mathrm{II}){ }^{37}$ Based on this model, the rate constant $(k)$ of NHPC is calculated to be $4.57 \mathrm{~g} \mathrm{mg}^{-1} \mathrm{~h}^{-1}$, almost 17 -fold that of Norit CGP $\left(0.27 \mathrm{~g} \mathrm{mg}^{-1} \mathrm{~h}^{-1}\right)$, further confirming that the NHPC possesses a high adsorption rate for the removal of phenol.

To further investigate the adsorption process of NHPC, the thermodynamics parameters including $\Delta G, \Delta H$ and $\Delta S$ were calculated according to eqn (6) and (7). As shown in Table 4, the negative $\Delta G$ value at each temperature (303 K, $313 \mathrm{~K}$ and $323 \mathrm{~K}$ ) indicates that the phenol adsorption on NHPC is a spontaneous

Table 2 Parameters of Langmuir and Freundlich models for the adsorption of phenol on NHPC and Norit CGP

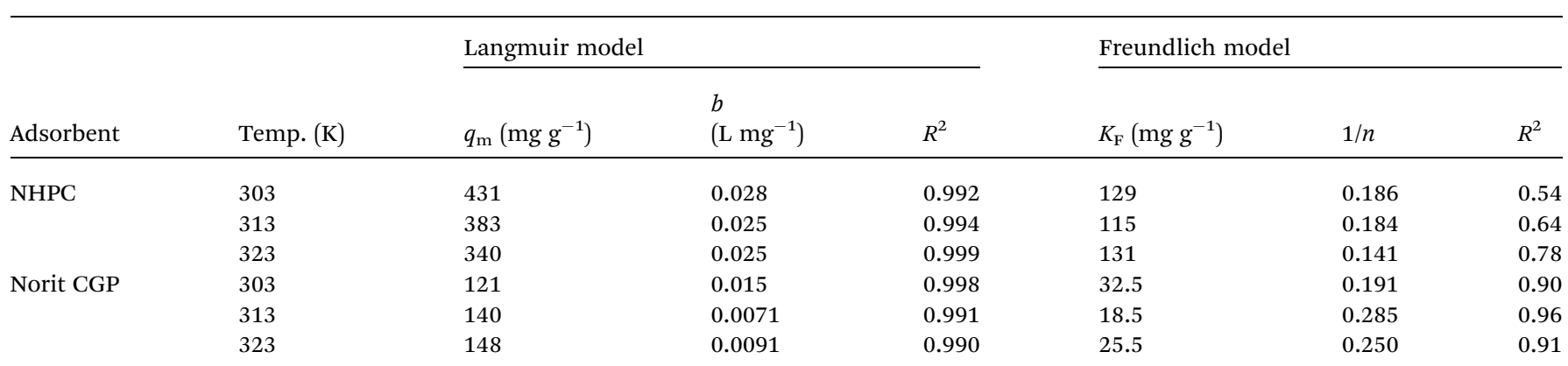


Table 3 Parameters of the pseudo-first-order and pseudo-secondorder models for the adsorption of phenol on NHPC

\begin{tabular}{lllllll}
\hline & & \multicolumn{3}{c}{$\begin{array}{l}\text { Pseudo first } \\
\text { order }\end{array}$} & & \multicolumn{2}{l}{ Pseudo second order } \\
Sample & Temp. (K) & $k_{1}\left(\mathrm{~h}^{-1}\right)$ & $R^{2}$ & & $k_{2}\left(\mathrm{~g} \mathrm{mg}^{-1} \mathrm{~h}^{-1}\right)$ & $R^{2}$ \\
\hline NHPC & 303 & 1.50 & 0.818 & 4.57 & 0.99996 \\
Norit CGP & 303 & 0.57 & 0.844 & 0.27 & 0.99998
\end{tabular}

Table 4 Thermodynamic parameters for the adsorption of phenol on NHPC

\begin{tabular}{llllll}
\hline & & & \multicolumn{4}{c}{$\Delta G^{\mathrm{o}}\left(\mathrm{kJ} \mathrm{mol}^{-1}\right)$} \\
\cline { 3 - 5 } Sample & $\begin{array}{l}\Delta H^{\mathrm{o}} \\
\left(\mathrm{kJ} \mathrm{mol}^{-1}\right)\end{array}$ & $\begin{array}{l}\Delta S^{\mathrm{o}}(\mathrm{J} \\
\left.\mathrm{K}^{-1} \mathrm{~mol}^{-1}\right)\end{array}$ & $30^{\circ} \mathrm{C}$ & $40^{\circ} \mathrm{C}$ & $50{ }^{\circ} \mathrm{C}$ \\
\hline NHPC & -3.98 & 52.1 & -19.8 & -20.2 & -20.9
\end{tabular}

process. Furthermore, the adsorption capacity decreases with increasing the adsorption temperature, suggesting that the phenol adsorption on NHPC is an exothermic process, which is also verified by the negative value of $\Delta H\left(-3.98 \mathrm{~kJ} \mathrm{~mol}^{-1}\right)$. This feature is different from the endothermic adsorption of $\mathrm{Pb}$ (II) ions from waste water. ${ }^{37}$

\subsection{Recyclability of NHPC}

The recyclability is an important factor that determines the application potential of the adsorbent for the removal of phenol. We further evaluated the recyclability of NHPC and Norit CGP towards phenol removal by the regeneration experiment at room temperature with regeneration of NHPC and Norit CGP in ethanol aqueous solution. As expected, the NHPC adsorbent (Fig. 4) exhibits a superior recyclability with approximately $98 \%$ of its initial adsorption capacity after 5 cycles, whereas the Norit CGP retains only $75 \%$ of its initial adsorption

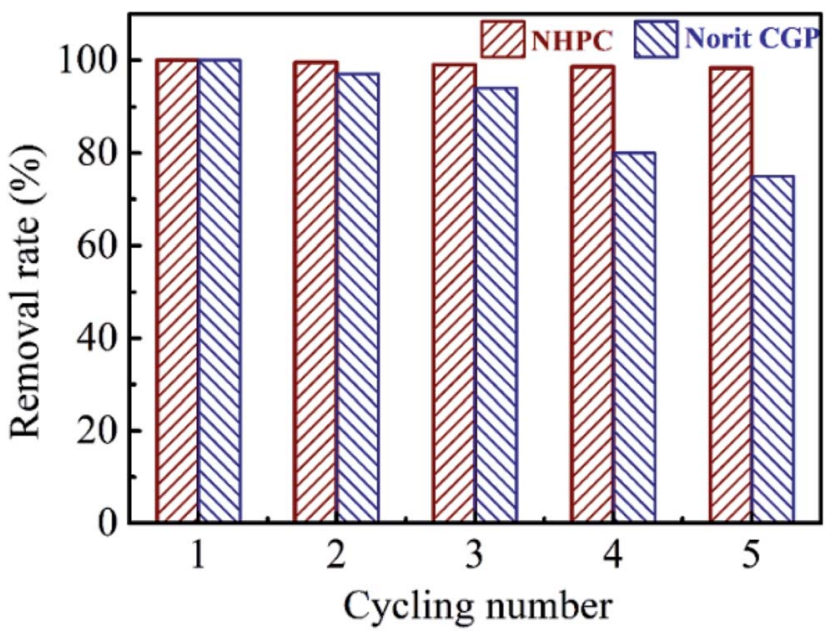

Fig. 4 The removal rate of NHPC and Norit CGP for phenol at different adsorption-desorption cycles. capacity. The remarkably superior recyclability of NHPC compared with Norit CGP is mainly attributed to its 3D hierarchically porous structure with interconnected open meso/ macropores networks that promotes not only adsorption of phenol into NHPC but also desorption of phenol from NHPC. Therefore, the NHPC possesses a remarkably large adsorption capacity over a wide $\mathrm{pH}$ range, high adsorption rate, and superior recyclability of phenol solution, making it a promising adsorbent for potential large-scale application for the removal of phenol.

\section{Conclusions}

In summary, we have developed a facile and effective strategy for synthesis of nitrogen-doped hierarchically porous carbon (NHPC) networks as highly efficient adsorbent for the removal of phenol from wastewater via the carbonization and $\mathrm{KOH}$ activation of cattle bone. The well-defined 3D hierarchical porous structure with a large specific surface area of $2687 \mathrm{~m}^{2} \mathrm{~g}^{-1}$ not only facilitates the quick transfer of the phenol molecules in the pore, but also provides sufficient accessible adsorption sites for the adsorption of phenols. Moreover, the doped nitrogen atoms in NHPC further promote the adsorption of phenol via the formation of donor-acceptor complex with phenol molecule by donating the lone pair electrons. Consequently, the NHPC exhibits a remarkable adsorption performance with a significantly larger adsorption capacity, a higher adsorption rate and a superior recyclability in comparison with Norit CGP. Furthermore, the NHPC is robust against the $\mathrm{pH}$ variation of phenol solution, exhibiting almost the identical maximum adsorption capacity over a wide $\mathrm{pH}$ range of 2-9. Thermodynamic and kinetic analyses indicate that the adsorption of phenol on NHPC is well defined by the Langmuir isotherm model and pseudo-second-order model, and the adsorption process is spontaneous and exothermic. This work develops a low-cost and effective methodology for the design and synthesis of hierarchically porous carbon adsorbents with superior adsorption performance for removal of phenol.

\section{Conflicts of interest}

There are no conflicts to declare.

\section{Acknowledgements}

This work was supported by National Natural Science Funds of China (No. 51432003).

\section{References}

1 S. Yuan, J. Gu, Y. Zheng, W. Jiang, B. Liang and S. O. Pehkonen, J. Mater. Chem. A, 2000, 3, 4620.

2 M. Hemmati, N. Nazari, A. Hemmati and S. Shirazian, J. Ind. Eng. Chem., 2015, 21, 1410.

3 J. E. Casillas, F. Tzompantzi, S. G. Castellanos, G. MendozaDamián, R. Pérez-Hernández, A. López-Gaona and A. Barrera, Appl. Catal., B, 2017, 208, 161. 
4 W. Tang, H. Huang, Y. Gao, X. Liu, X. Yang, H. Ni and J. Zhang, Mater. Des., 2015, 88, 1191.

5 M. H. Dehghani, M. Mostofi, M. Alimohammadi, G. McKay, K. Yetilmezsoy, A. B. Albadarin, B. Heibati, M. AlGhouti, N. M. Mubarak and J. N. Sahu, J. Ind. Eng. Chem., 2016, 35, 63.

6 N. K. Mondal, R. Bhaumik, B. Das, P. Roy, J. K. Datta, S. Bhattacharyya and S. Bhattacharjee, Appl. Water Sci., 2014, 5, 271.

7 O. G. Apul and T. Karanfil, Water Res., 2015, 68, 34.

8 B. Chang, W. Shi, D. Guan, Y. Wang, B. Zhou and X. Dong, Mater. Lett., 2014, 126, 13.

9 M. Wisniewski, A. P. Terzyk, P. A. Gauden, K. Kaneko and Y. Hattori, J. Colloid Interface Sci., 2012, 381, 36.

10 W. Bunmahotama, W.-N. Hung and T.-F. Lin, Water Res., 2015, 85, 521.

11 G. Yang, L. Tang, G. Zeng, Y. Cai, J. Tang, Y. Pang, Y. Zhou, Y. Liu, J. Wang, S. Zhang and W. Xiong, Chem. Eng. J., 2015, 259, 854.

12 K. Lamia and B. Farida, J. Chem. Eng. Data, 2010, 55, 4677.

13 L. A. Rodrigues, M. L. C. P. da Silva, M. O. Alvarez-Mendes, A. d. R. Coutinho and G. P. Thim, Chem. Eng. J., 2011, 174, 49.

14 J. Feng, K. Qiao, L. Pei, J. Lv and S. Xie, Ecol. Eng., 2015, 84, 209.

15 K. Mohanty, D. Das and M. N. Biswas, Chem. Eng. J., 2005, 115, 121.

16 G. Yang, H. Chen, H. Qin and Y. Feng, Appl. Surf. Sci., 2014, 293, 299.

17 A. D. browski, P. Podkościelny, Z. Hubicki and M. Barczak, Chemosphere, 2005, 58, 1049.

18 E. Lorenc-Grabowska, G. Gryglewicz and M. A. Diez, Fuel, 2013, 114, 235.

19 M. Dou, D. He, W. Shao, H. Liu, F. Wang and L. Dai, Chem.Eur. J., 2016, 22, 2896.
20 U. Soni, J. Bajpai, S. K. Singh and A. K. Bajpai, J. Water. Process Eng., 2017, 16, 56.

21 J. Sun, Z. Zhang, J. Ji, M. Dou and F. Wang, Appl. Surf. Sci., 2017, 405, 372.

22 H. Liu, Y. Cao, F. Wang and Y. Huang, ACS Appl. Mater. Interfaces, 2014, 6, 819.

23 S. Wei, D. Li, Z. Huang, Y. Huang and F. Wang, Bioresour. Technol., 2013, 134, 407.

24 H. N. Tran, S.-J. You, A. Hosseini-Bandegharaei and H.-P. Chao, Water Res., 2017, 120, 88.

25 A. Gundogdu, C. Duran, H. B. Senturk, M. Soylak, D. Ozdes, H. Serencam and M. Imamoglu, J. Chem. Eng. Data, 2012, 57, 2733.

26 L. Giraldoa and J. C. Moreno-Piraján, J. Anal. Appl. Pyrolysis, 2014, 106, 41.

27 Q. Miao, Y. Tang, J. Xu, X. Liu, L. Xiao and Q. Chen, J. Taiwan Inst. Chem. Eng., 2013, 44, 458.

28 K.-H. Park, M. S. Balathanigaimani, W.-G. Shim, J.-W. Lee and H. Moon, Microporous Mesoporous Mater., 2010, 127, 1.

29 Lalhmunsiama, D. Tiwari and S.-M. Lee, Chem. Eng. J., 2016, 283, 1414.

30 B. N. Bhadra, I. Ahmed and S. H. Jhung, Fuel, 2016, 174, 43.

31 J. Pal, M. K. Deb and D. K. Deshmukh, Res. Chem. Intermed., 2014, 41, 8363.

32 B. H. Hameed and A. A. Rahman, J. Hazard. Mater., 2008, 160, 576.

33 A. Kumar, S. Kumar, S. Kumar and D. V. Gupta, J. Hazard. Mater., 2007, 147, 155.

34 B. Ozkaya, J. Hazard. Mater., 2006, 129, 158.

35 V. C. Srivastava, M. M. Swamy, I. D. Mall, B. Prasad and I. M. Mishra, Colloids Surf., A, 2006, 272, 89.

36 H. J. He, Z. H. Xiang, X. J. Chen, H. Chen, H. Huang, M. Wen and C. P. Yang, Int. J. Environ. Sci. Technol., 2017, DOI: 10.1007/s13762-017-1507-8.

37 Y. Cheng, C. Yang, H. He, G. Zeng, K. Zhao and Z. Yan, J. Environ. Eng., 2016, 142, C4015001. 